had high risk of bias, small sample size and low quality (Level 2 evidence) with high attrition rate but it revealed reduction of daily prednisolone with Azathioprine. A high quality RCT (Level 1) did not confirm a steroid sparing effect with Infliximab vs placebo, and there was no significant difference between relapse or remission rate. Methotrexate studies showed conflicting results: one high quality RCT (Level 1) and one low quality RCT (Level 2) on Methotrexate revealed statistically significant steroid sparing effect, however the remaining study did not demonstrate between Methotrexate and placebo. Two methotrexate studies assessed the risk of relapse, with conflicting results (relapses $73 \%$ placebo vs $47 \%$ methotrexate; or no difference).

Methotrexate was not associated with increased adverse effects in any of the studies. Azathioprine was associated with significant adverse events resulting in high attrition.

A meta analysis was not performed for methotrexate as the studies were heterogenous.

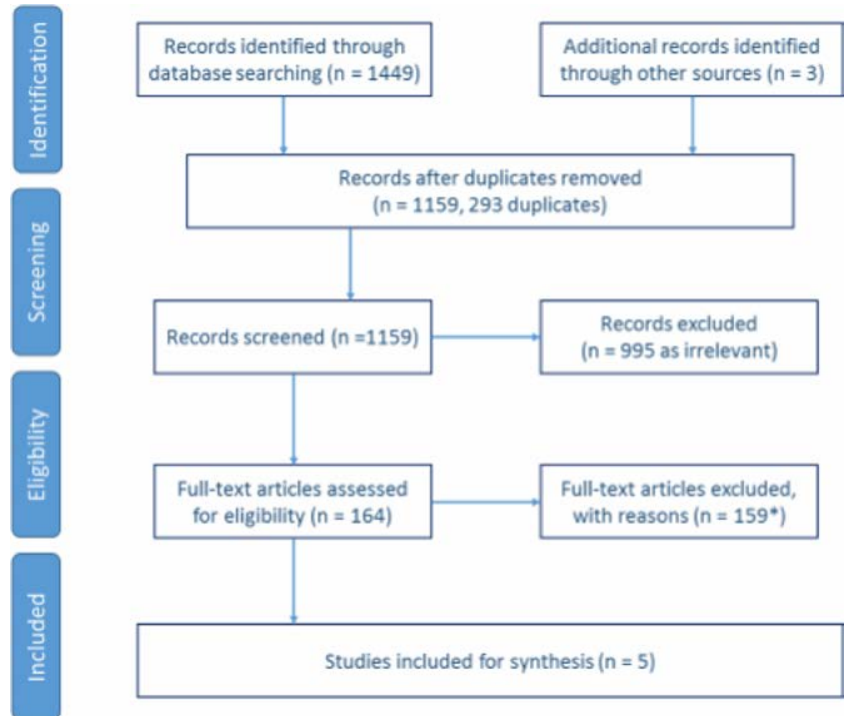

Conclusion: There is a lack of evidence regarding DMARDs and biologics in PMR. Methotrexate is an effective steroid sparing agent, and is not associated with increased adverse events. Azathioprine may be effective but is associated with significant adverse events. Infliximab is not an effective steroid sparing agent in PMR. More high quality RCTs are needed to study the efficacy of steroid sparing agents.

References:

[1] Bhaskar Dasgupta, Frances A. Borg, Nada Hassan, Kevin Barraclough, Brian Bourke, Joan Fulcher, Jane Hollywood, Andrew Hutchings, Valerie Kyle, Jennifer Nott, Michael Power, Ash Samanta, on behalf of the BSR and BHPR Standards, Guidelines and Audit Working Group, BSR and BHPR guidelines for the management of polymyalgia rheumatica, Rheumatology, Volume 49, Issue 1, January 2010, Pages 186-190

Disclosure of Interests: None declared

DOI: 10.1136/annrheumdis-2020-eular.4763

\section{FRI0476 RHEUMATIC MANIFESTATIONS DURING INFLAMMATORY BOWEL DISEASE}

M. Boudabbous $^{1}$, H. Gdoura ${ }^{1}$, L. Chtourou ${ }^{1}$, A. Amouri ${ }^{1}$, L. Mnif ${ }^{1}$, N. Tahri ${ }^{1}$. ${ }^{1}$ Hédi Chaker Hospital, Sfax University, Hepatogastroenterology, Sfax, Tunisia

Background: Rheumatologic manifestations are frequent extraintestinal manifestations (MEI) of chronic inflammatory bowel disease (IBD). Some of these manifestations develop in parallel with the underlying disease, others evolve on their own account. They sometimes lead to reconsider the initial therapy for intestinal purposes.

Objectives: The aim of our study is to specify the epidemioclinical characteristics of osteoarticular manifestations of chronic inflammatory bowel disease and their possible impact on intestinal disease

Methods: This is a retrospective study conducted between January 2000 and December 2015 including patients hospitalized in our department for chronic inflammatory bowel disease (IBD).

Results: During the study period, 206 patients with IBD were hospitalized in our department, 78 of whom had rheumatic MEI (frequency equal to $37.8 \%$ ). These 78 patients were divided into 48 men and 30 women with a sex ratio of 1.6 and an average age of $40.7 \pm 13.6$ years (18-79). They had Crohn's disease in $60 \%$ of the cases. The average length of service for IBDs was $83 \pm 73$ months (4-360). Osteoarticular MEls were peripheral in $56.4 \%$ of cases, axial in $29.5 \%$ of cases, mixed in $6.41 \%$ of cases with the presence of osteopenia in $6.41 \%$ of cases and osteoporosis in $128 \%$. The activity of IBD associated with these MEI was moderate with an average number of outbreaks / year of $1.6 \pm 0.8$. These patients were treated with salicylates in $30.7 \%$ of the cases using corticosteroid therapy at least once in $23 \%$ of the cases. Maintenance treatment based on immunosuppressants was found in $38.46 \%$ of cases and anti-TNF alfa in $10.25 \%$ of cases. During follow-up, 3 patients died (3.84\%). There was no significant difference between patients with IBD with rheumatic $\mathrm{MEI}$ and without rheumatic $\mathrm{MEI}$ regarding epidemiological data and disease activity.

Conclusion: Rheumatic MEls are found in almost $40 \%$ of IBDs. They affect men more frequently than women and Crohn's disease than UC. They are rather peripheral and do not associate with a more important activity of the disease.

\section{References:}

[1] Journal of the Canadian Association of Gastroenterology, 2019, 2(S1), S73S80 doi: 10.1093/jcag/gwy053 Supplement Article

Disclosure of Interests: None declared

DOI: 10.1136/annrheumdis-2020-eular.6114

\section{FRI0477 SYSTEMIC TREATMENT IN SARCOIDOSIS. STUDY OF 377 PATIENTS FROM A SINGLE UNIVERSITY HOSPITAL}

M. Calderón-Goercke ${ }^{1}$, R. Fernández-Ramón ${ }^{2}$, J. L. Martín-Varillas ${ }^{1}$,

L. Sanchez-Bilbao', D. Martínez-López¹, I. González-Mazón ${ }^{1}$, J. J. GaitánValdizán², R. Demetrio-Pablo², M. A. González-Gay ${ }^{1}$, R. Blanco ${ }^{1}{ }^{1} H U M$. Valdecilla, Rheumatology, Santander, Spain; ${ }^{2}$ HUM.Valdecilla, Ophthalmology, Santander, Spain

Background: Sarcoidosis is a multisystemic disease characterized by the formation of non-necrotizing granulomas. The most frequently affected organs are lungs, skin and eyes. Systemic corticosteroids are the most used drugs in the treatment of this disease. Conventional and biological immunosuppressants (IS) may also be used (1-3).

TABLE. Systemic treatment of sarcoidosis according to clinical domains.

\begin{tabular}{|c|c|c|c|c|c|c|c|c|c|c|c|c|c|c|c|c|c|}
\hline \multirow[b]{2}{*}{ ORGAN INVOLVEMENT } & \multicolumn{9}{|c|}{ CONVENTIONAL IS } & \multicolumn{8}{|c|}{ BIOLOGICAL IS } \\
\hline & Cases & NT & ocs & $\begin{array}{l}\text { MD of OCS } \\
(\mathrm{mg} / \mathrm{d})^{\star}\end{array}$ & IVMP & MTX & AZA & CFM & MMF & BT & IFX & ADA & ETN & GLM & $\mathrm{TCZ}$ & RTX & CR \\
\hline Pulmonary, n(\%) & $319(84.6)$ & $128(40.1)$ & $185(58)$ & $43.6 \pm 18.8$ & $13(4.1)$ & $46(14.4)$ & $13(4.1)$ & $2(0.6)$ & $3(0.9)$ & $21(6.6)$ & $12(3.8)$ & $16(5.0)$ & 0 & $1(0.3)$ & $2(0.6)$ & $3(0.9)$ & $64(33.5)$ \\
\hline Cutaneous, $n(\%)$ & $124(32.9)$ & $50(40.3)$ & $66(53.2)$ & $38.0 \pm 20.2$ & $4(3.2)$ & $18(14.5)$ & $4(3.2)$ & $1(0.8)$ & 0 & $9(7.3)$ & $5(4)$ & $9(7.3)$ & $1(0.8)$ & $2(4.2)$ & 0 & $1(0.8)$ & $29(39.2)$ \\
\hline Ocular, $n(\%)$ & $48(12.7)$ & $5(10.4)$ & $38(79.2)$ & $41.5 \pm 17.6$ & $10(20.8)$ & $23(47.9)$ & $8(16.7)$ & $1(2.1)$ & $1(2.1)$ & $13(27.1)$ & $5(10.4)$ & 11(22.9) & $1(2.1)$ & $2(4.2)$ & $2(4.2)$ & 0 & $10(23.3)$ \\
\hline Musculo-eskeletal, n(\%) & $108(28.6)$ & $41(38)$ & $65(60.2)$ & $39.2 \pm 18.7$ & $5(4.6)$ & $26(24.1)$ & $6(5.6)$ & 0 & 0 & $12(11.1)$ & $8(7.4)$ & $8(7.4)$ & $1(0.7)$ & $2(1.9)$ & 0 & $1(0.9)$ & $24(35.8)$ \\
\hline Hepatic, $n(\%)$ & $41(10,9)$ & 12(29.3) & $27(65,9)$ & $43.8 \pm 15.2$ & $3(7.3)$ & $6(14.6)$ & $1(2.4)$ & $1(2.4)$ & 0 & $1(2.4)$ & $1(2.4)$ & $1(2.4)$ & 0 & 0 & 0 & 0 & 6(20.7) \\
\hline Neurologic, $n(\%)$ & $27(7.2)$ & $4(14.8)$ & $23(85,2)$ & $50.9 \pm 20.2$ & $5(18.5)$ & $14(51.9)$ & $5(18.5)$ & 0 & 0 & $9(33.3)$ & $7(25.9)$ & $5(18.5)$ & 1(3.7) & $2(7.4)$ & 1(3.7) & 1(3.7) & $6(26.1)$ \\
\hline Cardiac, $n(\%)$ & $8(2.1)$ & $4(50)$ & $4(50)$ & $40.0 \pm 28.3$ & $1(12.5)$ & $2(25)$ & $1(12.5)$ & $1(12.5)$ & 0 & $2(25)$ & $2(25)$ & $2(25)$ & 0 & 0 & 0 & 0 & $1(25)$ \\
\hline Renal, $n(\%)$ & $22(5.8)$ & $2(9.1)$ & $20(90,9)$ & $47.1 \pm 13.8$ & $1(4.5)$ & $6(27.3)$ & $2(9.1)$ & 0 & 0 & $2(9.1)$ & $1(4.5)$ & $2(9.1)$ & 0 & 0 & 0 & 0 & $3(15)$ \\
\hline Löfgren's síndrome, $n(\%)$ & $44(11.7)$ & $18(40.9)$ & $24(54,5)$ & $29.8 \pm 15.3$ & 0 & $3(6.8)$ & $1(2.3)$ & 0 & 0 & $2(4.5)$ & $1(2.3)$ & $2(4.5)$ & 0 & 0 & 0 & $1(2.3)$ & $19(69.2)$ \\
\hline Heerfordt's síndrome, $n(\%)$ & $2(0.5)$ & 0 & $2(100)$ & $57.5 \pm 17.7$ & $2(100)$ & $2(100)$ & $1(50)$ & 0 & 0 & $2(100)$ & $2(100)$ & $2(100)$ & 0 & 0 & 0 & 0 & 0 \\
\hline TOTAL,n(\%) & $377(100)$ & $161(42.7)$ & $206(54.6)$ & $48.2 \pm 19.0$ & $15(4.0)$ & $53(14.1)$ & $16(4.2)$ & $2(0.5)$ & $3(0.8)$ & $28(7.4)$ & $15(4.0)$ & $20(5.3)$ & $1(0.3)$ & $2(0.5)$ & $3(0.8)$ & $3(0.8)$ & $72(33.3)$ \\
\hline
\end{tabular}

NT: no treatment; MD: maxim dose; OCS: oral corticosteroids; IVMP: intravenous methylprednisolone; BT: biological therapy, CR: complete response

${ }^{*}$ Mean $( \pm S D)$ 